TITLE:

\title{
Dietary flavonoids suppress azoxymethane-induced colonic preneoplastic lesions in male C57BL/KsJ-db/db mice
}

\section{$\operatorname{AUTHOR}(\mathrm{S})$ :}

Miyamoto, Shingo; Yasui, Yumiko; Ohigashi, Hajime; Tanaka, Takuji; Murakami, Akira

\section{CITATION:}

Miyamoto, Shingo ... [et al]. Dietary flavonoids suppress azoxymethane-induced colonic preneoplastic lesions in male C57BL/KsJ-db/db mice. Chemico-Biological Interactions 2010, 183(2): 276-283

\section{ISSUE DATE:}

2010-01

URL:

http://hdl.handle.net/2433/91256

\section{RIGHT:}

c 2009 Elsevier Ireland Ltd. All rights reserved.; この論文は出版社版であ りません。引用の際には出版社版をご確認ご利用ください。; This is not the published version. Please cite only the published version. 
1 Dietary flavonoids suppress azoxymethane-induced colonic preneoplastic lesions in male C57BL/KsJ-db/db mice

3

Shingo Miyamoto ${ }^{a}$, Yumiko Yasui ${ }^{b}$, Hajime Ohigashi ${ }^{a, c}$, Takuji Tanakab and Akira

5 Murakami $i^{\mathbf{a}, \mathbf{d}}$

6

7 a Division of Food Science and Biotechnology, Graduate School of Agriculture,

8 Kyoto University, Kyoto 606-8502, Japan

9 bepartment of Oncologic Pathology, Kanazawa Medical University, 1-1 Daigaku, 10 Uchinada, Ishikawa 920-0293 and The Tohkai Cytopathology Institute: Cancer 11 Research and Prevention (TCI-CaRP), 4-33 Minami-Uzura, Gifu 500-8285, Japan

$12{ }^{\text {C}}$ Present address: Faculty of Biotechnology, Fukui Prefectural University, Japan ${ }^{\mathrm{d}}$ Corresponding author. Division of Food Science and Biotechnology, Graduate

14 School of Agriculture, Kyoto University, Kyoto 606-8502, Japan E-mail address: cancer@kais.kyoto-u.ac.jp

17 Running title: Dietary flavonoids inhibit the early phase of colon carcinogenesis in $18 d b / d b$ mice

Key words: flavonoid; ACF; BCAC; colon carcinogenesis; $d b / d b$ mice

21 Abbreviations: ACF, aberrant crypt foci; AOM, azoxymethane; BCAC, $\beta$-catenin

22 accumulated crypt; IGF-1, insulin-like growth factor-1; PCNA, proliferating cell 23 nuclear antigen; C/EBP, CCAAT/enhancer binding protein; PPAR, peroxisome 24 proliferator-activated receptor 
Miyamoto 2

\section{Abstract}

2 Obesity is known to be a risk factor for colon carcinogenesis. Although there are

3 several reports on the chemopreventive abilities of dietary flavonoids in chemically

4 induced colon carcinogenesis, those have not been addressed in an obesity-associated

5 carcinogenesis model. In the present study, the effects of 3 flavonoids on modulation of

6 the occurrence of putative preneoplastic lesions, aberrant crypt foci (ACF), and

$7 \beta$-catenin accumulated crypts (BCACs) in the development of colon cancer were

8 determined in male $d b / d b$ mice with obesity and diabetic phenotypes. Male $d b / d b$ mice

9 were given 3 weekly intraperitoneal injections of azoxymethane (AOM) to induce the

10 ACF and BCAC. Each flavonoid (100 ppm), given in the diet throughout the

11 experimental period, significantly reduced the numbers of ACF by $68-91 \%$ and BCAC

12 by $64-71 \%$, as well as proliferation activity in the lesions. Clinical chemistry results

13 revealed that the serum levels of leptin and insulin in mice treated with AOM were

14 greater than those in the untreated group. Interestingly, the most pronounced

15 suppression of development of preneoplastic lesions and their proliferation were

16 observed in the quercetin-fed group, in which the serum leptin level was lowered.

17 Furthermore, quercetin-feeding decreased leptin mRNA expression and secretion in

18 differentiated 3T3-L1 mouse adipocytes. These results suggest that the present dietary

19 flavonoids are able to suppress the early phase of colon carcinogenesis in obese mice,

20 partly through inhibition of proliferation activity caused by serum growth factors.

21 Furthermore, they indicate that certain flavonoids may be useful for prevention of colon

22 carcinogenesis in obese humans. 
Miyamoto 3

\section{Introduction}

2

4 types of cancer, including colorectal cancer [1]. Recently, a prospective population

5 based study of about 90000 subjects conducted by the American Cancer Society

6 confirmed that obesity is directly associated with an increased risk of death from colon

7 cancer [2]. In addition, animal studies have also suggested that obesity enhances tumor

8 development [3], while calorie restriction was reported to inhibit a broad range of

9 spontaneous, transplanted, and chemically induced neoplasms [4].

10 Leptin, a 16-kDa protein encoded by the ob gene, was first documented in 1994 as a

11 regulator of body weight gain and energy balance, with its activities displayed in the

12 hypothalamus [5]. It is well known that serum leptin levels are highly elevated in obese

13 individuals [6] and the protein is mainly secreted by white adipocytes [7].

$14 \mathrm{C} 57 \mathrm{BL} / \mathrm{KsJ}-d b / d b(d b / d b)$ mice are often used as a genetically altered animal model

15 with the genotypes of obesity and diabetes mellitus [8]. In this mouse strain, a mutation

16 in the cytoplasmic domain of the long form of the leptin receptor (Ob-Rb) results in loss

17 of expression of this isoform [9]. In the absence of Ob-Rb, the mice eat excessively and

18 are already obese at 4 weeks of age. Furthermore, they are also demonstrate

19 hyperleptinemia, hyperinsulinemia, hyperglycemia, and hyperlipidemia, as well as

20 increased levels of cholesterol in plasma [10]. The synthesis of leptin in adipocytes,

21 which may be involved in neoplastic processes, is influenced by insulin, tumor necrosis

22 factor- $\alpha$, glucocorticoids, reproductive hormones, and prostaglandins [11]. In addition,

23 leptin can act as a growth factor in colonic epithelial cells [12], while it also modulates

24 the proliferation of colonic cryptal cells [13]. Since leptin might be one of the biological 
1 factors involved in the development of colorectal cancer associated with

2 obesity/diabetes, $d b / d b$ mice are quite useful as a model for elucidating the relationship

3 between colon carcinogenesis and obesity/diabetes.

$4 \quad$ Flavonoids comprise a structurally diverse class of polyphenolic compounds

5 ubiquitously found in plants and produced as a result of plant secondary metabolism

6 [14]. They have several biological effects, such as anti-oxidative and anti-inflammatory

7 activities [15]. We previously reported that chrysin [16], quercetin [17], and nobiletin

8 [18] showed chemopreventive effects toward azoxymethane (AOM)-induced colon

9 carcinogenesis in rats. In addition, administration of green tea polyphenols, including

10 epicatechin, epicatechin gallate, epigallocatechin, and epigallocatechin gallate, resulted

11 in a significant reduction in body weight gain and body fat accumulation in rodents [19,

12 20]. Furthermore, an in vitro study found that certain flavonoids inhibit the growth of

13 3T3-L1 pre-adipocytes [21]. However, there are known no studies of the effects of

14 flavonoids on obesity-associated carcinogenesis.

15 In the present study, we first determined the modulatory effects of 6 different

16 flavonoids; flavone, chrysin, apigenin, luteolin, quercetin, and nobiletin (Figure 1A), on

17 leptin secretion from 3T3-L1 cells. Next, we evaluated the effects of dietary chrysin, 18 quercetin, and nobiletin on the occurrence of AOM-induced aberrant crypt foci (ACF)

19 and $\beta$-catenin-accumulated crypts (BCACs), putative precursor lesions for colonic

20 adenocarcinoma $[22,23]$, in $d b / d b$ male mice. We also investigated those 3 flavonoids

21 to determine their effects on clinical chemistry related to the occurrence of colorectal

22 cancer [24]. Since we previously observed high proliferation activities in preneoplastic

23 colonic lesions and non-lesional crypts in $d b / d b$ mice [25], the effects of these

24 flavonoids in regard to proliferation activity in ACF and BCAC were analyzed using an 
immunohistochemical methods.

2

\section{Materials and Methods}

5 Cell culture

6 3T3-L1 mouse pre-adipocytes were obtained from the American Type Culture

7 Collection (ATCC, Manassas, VA). The cells were maintained in Duibecco’s Modified

8 Eagle Medium (DMEM) supplemented with 10\% bovine serum (BS), as well as 100

$9 \mathrm{U} / \mathrm{ml}$ of penicillin and $100 \mu \mathrm{g} / \mathrm{ml}$ of streptomycin at $37^{\circ} \mathrm{C}$ in a humidified $5 \% \mathrm{CO}_{2}$ 10 atmosphere.

Intracellular lipid accumulation and leptin secretion

3T3-L1 cells ( 1 x 10 $/ 200 \mu \mathrm{l} /$ well) were seeded into 96-well plates under the growth conditions described above. After reaching confluence, they were incubated for an additional 24 hours (designated as day 0). Then, adipocyte differentiation was induced by treatment with a mixture of methylisobutylxanthine $(0.5 \mathrm{mM})$, dexamethasone (1

$17 \mu \mathrm{M})$, and insulin $(10 \mu \mathrm{g} / \mathrm{ml})$, components of an Adipogenesis Assay Kit (Chemicon

18 International, Temecula, CA), in DMEM containing 10\% FBS for 48 hours. The 19 medium was then replaced by DMEM containing 10\% fetal bovine serum (FBS) and 20 insulin $(5 \mu \mathrm{g} / \mathrm{ml})$, and changed to fresh medium every 2 days, according to a method 21 previously described by Maeda et al. [26], with some modifications. On day 2, each 22 flavonoid (10, 50, and $100 \mu \mathrm{M})$ was dissolved in dimethyl sulfoxide (DMSO), then 23 added to DMEM containing FBS and insulin. The final concentration of DMSO was $24 \quad 0.1 \%(v / v)$, which was found to have no effect on cell growth (data not shown). After 12 
Miyamoto 6

1 days, the medium was collected and subjected to ELISA to determine the levels of

2 leptin. The cells were stained with the Oil Red-O component of an Adipogenesis Assay

3 Kit, according to the manufacturer's instructions. Stained oil droplets in 3T3-L1 cells

4 were extracted with dye extraction solution and absorbance of the extracts was

5 measured at $490 \mathrm{~nm}$.

6

$7 \quad$ Mice, diet, and carcinogens

8 Male $d b / d b$ mice were obtained from Jackson Laboratories (Bar Harbor, ME) at the

9 age of 4 weeks and maintained at the Kanazawa Medical University Animal Facility

10 according to the Institutional Animal Care Guidelines. On arrival, all mice were

11 randomized and transferred to plastic cages (2 or 3 mice/cage), and given free access to

12 drinking water and a pelleted basal diet (CRF-1, Oriental Yeast Co., Tokyo, Japan),

13 under controlled conditions of humidity (50 \pm 10\%), light (12/12 hour light/dark cycle),

14 and temperature $\left(23 \pm 2^{\circ} \mathrm{C}\right)$. All mice were quarantined for 1 week before starting the

15 experiment. Nobiletin (>98\% purity) was obtained from Nard Chemicals (Hyogo,

16 Japan), while other flavonoids were purchased from WAKO Pure Chemicals (Osaka,

17 Japan). Experimental diets were prepared by mixing each flavonoid (100 ppm)

18 separately with powdered CRF-1 every week during the study. Azoxymethane (AOM),

19 a colonic carcinogen, was purchased from Sigma Chemical Co. (St. Louis, MO).

21 Experimental procedures

22 All mice were divided into the following 8 experimental and control groups: AOM

23 alone (group 1, n=9); AOM + chrysin (group 2, n=10); AOM + quercetin (group 3,

$24 \mathrm{n}=10$ ); $\mathrm{AOM}+$ nobiletin (group 4, $\mathrm{n}=10$ ); chrysin alone (group 5, $\mathrm{n}=5$ ); quercetin alone 
1 (group 6, $n=5$ ); nobiletin alone (group 7, $n=5$ ); and untreated (group 8, $n=5$ ). The mice

2 in groups 1-4 were given 3 weekly intraperitoneal injections of AOM (15 mg/kg body 3 weight), while those in groups 2 through 7 were fed the experimental diets containing 4 the flavonoids (100 ppm) for the entire 10-week experimental period. Groups 1 and 2 5 were given the basal diet without flavonoids during the study. At week 10, all mice were 6 euthanized after overnight fasting by an intraperitoneal injection of sodium 7 pentobarbital (1 $\mathrm{mg} / \mathrm{kg}$ body weight). Blood samples were taken from the portal vein

8 before the mice were killed. A complete necropsy was done, and all organs, including 9 the colon, were removed, with the liver, kidneys, pancreas, and epididymal adipose 10 tissue weighted.

Counting colonic ACF and BCAC

The numbers of ACF and BCAC were determined according to standard procedures described previously $[27,28]$. Briefly, the colons were cut, placed on filter paper with the mucosal surface up, and fixed in $10 \%$ buffered formalin for at least 24 hours. The fixed colons were stained with methylene blue (0.5\% in distilled water) for 20 seconds, dipped in distilled water, and placed on microscope slides to count the number and determine the size of ACF. Rectal mucosa (2.0 cm from the anus) was embedded in paraffin to identify intramucosal lesions, considered to be BCAC. A total of 20 serial sections (4 $\mu \mathrm{m}$ thick each) per rectum were prepared using an en face method [28]. For each mouse, 2 serial sections were used to analyze the BCAC. The numbers of BCAC

22 in histological sections stained with $\beta$-catenin were counted and are expressed as the number of BCAC per $\mathrm{cm}^{2}$ of mucosa. 
Miyamoto 8

1

2

3

4

5 minutes at $65^{\circ} \mathrm{C}$, deparaffinized in xylene, and rehydrated through a graded series of

6 alcohol at room temperature. A 0.05-M Tris-HCl buffer ( $\mathrm{pH}$ 7.6) was used to prepare the

7 solutions and for washing between the steps. The sections were treated for 40 minutes at

8 room temperature with $2 \%$ bovine serum albumin and incubated overnight at $4^{\circ} \mathrm{C}$ with

9 the primary antibody against $\beta$-catenin protein (diluted 1:1000, BD Transduction

10 Laboratories, Lexington, KY). Horseradish peroxidase activity was visualized by

11 treatment with $\mathrm{H}_{2} \mathrm{O}_{2}$ and diaminobenzidine for 5 minutes. Negative-control sections were immunostained without the primary antibody. Immunoreactivity to determine the presence of BCAC was regarded as positive if apparent staining was detected in the cytoplasm and/or nuclei.

For PCNA immunohistochemistry, formalin-fixed, paraffin-embedded distal colon sections were subjected to deparaffinization and dehydration prior to quenching of endogenous peroxidase activity (1.5\% $\mathrm{H}_{2} \mathrm{O}_{2}$ in methanol for 20 minutes). An antigen-unmasking step was done by placing the slides in a pressure cooker containing $0.01 \mathrm{M}$ sodium citrate ( $\mathrm{pH}$ 6.0) for 10 minutes. The sections were incubated for 60 minutes with the primary mouse anti-rat PCNA monoclonal antibody (Clone PC-10, DakoCytomation) at a dilution of $1: 1500$ in $10 \%$ goat serum. A secondary antibody, biotinylated goat anti-mouse IgG (Vector Laboratories, Burlingame, CA), was then applied for 30 minutes in a 1:500 dilution. Slides were processed with ABC reagent from a Vectastain Elite kit (Vector Laboratories) using DAB as the substrate. Using 
Miyamoto 9

1 distal colonic mucosa without lesions from 5 mice in each group, 20 fields were

2 randomly selected from each slide and analyzed at 400x magnification. PCNA-positive

3 cell nuclei were determined in 10 ACF and 10 BCAC each from groups 1 through 4 .

4 Cells stained positive for PCNA were scored and expressed as a percentage of total cells

5 in each lesion.

6

$7 \quad$ Clinical chemistry

8 The collected blood samples were used for clinical chemistry. Leptin (Quantikine

9 Mouse leptin, ELISA/Assay Kit, R\&D Systems Inc.), adiponectin (Mouse/Rat 10 adiponectin ELISA kit, Otsuka Pharmaceutical Co., Ltd., Tokyo, Japan), insulin-like 11 growth factor (IGF)-1 (Quantikine Mouse IGF-1, ELISA/Assay Kit, R\&D Systems Inc.), 12 insulin (Insulin measurement kit, Morinaga Institute of Biological Science), 13 triglycerides (Triglyceride E-test, Wako Pure Chemical Industries), cholesterol

14 (Cholesterol E-test, Wako Pure Chemical Industries), and glucose (Glucose CII-test 15 Wako, Wako Pure Chemical Industries) levels were measured. Serum samples without 16 dilution were used for determining insulin, triglycerides, cholesterol, and glucose, while 17 those diluted 100-, 10201-, and 500-fold were used for determining the levels of leptin, 18 adiponectin, and IGF-1, respectively.

Western blotting

21 3T3-L1 cells $\left(1 \times 10^{5} / 3 \mathrm{ml} / \mathrm{dish}\right)$ were seeded into $35-\mathrm{mm}$ dishes following 22 treatment with quercetin or nobiletin, then washed twice with PBS and lysed in lysis 23 buffer [10-nM Tris (pH 7.4), 1\% sodium dodecyl sulfate (SDS), 1-mM sodium 24 metavanadate (V)], and centrifuged at $3200 \mathrm{x}$ g for 5 minutes. Denatured proteins (40 
Miyamoto 10

$1 \mu \mathrm{g})$ were separated using SDS-PAGE on a $10 \%$ polyacrylamide gel and then transferred

2 onto Immobilon-P membranes (Millipore, Billerica, MA). After blocking with Block

3 Ace (Snow Brand Milk Products, Tokyo, Japan) for 1 hour, the membranes were reacted

4 with the appropriate specific primary antibody (1:1000), followed by the corresponding

5 HRP-conjugated secondary antibody (1:1000). The blots were developed using ECL

6 Western blotting detection reagents. Antibodies directed against Pi- mitogen-activated

7 protein kinase/ extracellular signaling-regulated kinase (MEK)1/2 (Ser217/221),

8 Pi-extracellular signaling-regulated kinase (ERK)1/2 (Thr202/Tyr204), Pi-mammalian

9 target of rapamycin (mTOR) (Ser2448), Pi-S6 (Ser240/244), and Pi-eukaryotic initiation

10 factor 4B (eIF4B) (Ser422), as well as horseradish peroxidase (HRP)-conjugated

11 anti-rabbit antibody, were obtained from Cell Signaling Technology (Beverly, MA).

Reverse transcription-polymerase chain reaction (RT-PCR)

Total RNA was extracted from the cells under the same conditions used for Western blotting using TRIzol reagent, according to the manufacturer's instructions. cDNA was synthesized using $1 \mu \mathrm{g}$ of total RNA and an RNA PCR Kit (AMV). PCR amplification was performed using a thermal cycler (PTC- $100^{\mathrm{TM}}$, MJ Research, Watertown, MA), and conducted with each sense and antisense primer. The primer sequences and PCR conditions are listed in Table 1. A cyclophilin transcript served as the internal control. PCR products were subjected to electrophoresis through 3\% agarose gels and stained

21 with SYBR ${ }^{\circledR}$ Gold.

Statistical analysis

24 Where applicable, data were analyzed using a Tukey-Kramer multiple comparison 
1 test (GraphPad InStat version 3.05, GraphPad Software, San Diego, CA), Fisher’s exact

2 probability test, and Student's $t$-test (two-sided), with $P<0.05$ as the criterion of

3 significance.

\section{Results}

6

$7 \quad$ Modulatory effects of flavonoids on Oil Red-O staining and leptin secretion

8 Adipocyte differentiation was induced by treatment with a mixture of 3-isobutyl-1-

9 methylxanthine, dexamethasone, and insulin in DMEM containing 10\% FBS for 48

10 hours, after which differentiated 3T3-L1 adipocytes were separately treated with the 6

11 flavonoids $(10 \mu \mathrm{M})$ or the vehicle for 12 days to determine their effects on intracellular

12 lipid accumulation and leptin secretion. Differentiated 3T3-L1 cells were notably loaded

13 with lipid, as detected by Oil Red-O staining, whereas none of the flavonoids had

14 noticeable effects (Figure 1B). On the other hand, quercetin and nobiletin significantly

15 reduced leptin secretion $(P<0.01$, Figure $1 \mathrm{~B})$, with the reduction by nobiletin

16 remarkable.

18 General observations of in vivo experiment

19 We selected 3 of the flavonoids, chrysin, quercetin, and nobiletin, for the in vivo

20 experiment based on their chemopreventive efficacy previously shown in colon

21 carcinogenesis models [16-18], together with the present data regarding leptin secretion

22 (Figure 1B). To investigate the effects of these flavonoids on the early phase of

23 obesity-related carcinogenesis and serum levels of leptin, we performed short-term in

24 vivo assays using histological biomarkers, ACF and BCAC, in the $d b / d b$ mice. During 
1 the study, dietary feeding with the flavonoids did not cause clinical symptoms, including

2 toxicity (data not shown). Food consumption did not significantly differ among the

3 groups. In addition, we did not observe significant changes in regard to body weight

4 gain, epididymal fat weight, or colon length (Table 2). In contrast, the pancreas weight

5 was significantly increased in group $3(\mathrm{AOM}+$ quercetin, $P<0.05)$ when compared

6 with group 1 (AOM alone).

7

8 Frequency of preneoplastic lesions (ACF and BCAC) and PCNA-labeling index

9 Histological examinations revealed no pathological lesions in any organs except the 10 colon. Table 3 summarizes data for colonic ACF and BCAC formation. All mice in 11 groups 1 through 4, which received AOM with or without a flavonoid, developed ACF.

12 In groups 5 through 8 , there were no microscopically observable changes, including 13 ACF and BCAC, in our examinations of colonic morphology. The mean number $( \pm \mathrm{SD})$ 14 of ACF per colon in group 1 was $25.6 \pm$ 8.9. Dietary administration of chrysin, 15 quercetin, and nobiletin significantly reduced ACF incidence by $91 \%$, 89\%, and 68\%, 16 respectively ( $P<0.001$ versus group 1$)$, while we also saw a significant reduction 17 (85-100\% inhibition, $P<0.001)$ in the numbers of large ACF containing 4 or more 18 aberrant crypts, which are known to be well-correlated with the incidence of colonic 19 adenocarcinoma [29-31], when compared with group 1 (12.5 \pm 9.7$)$. Also, large ACF did not develop in the colons of mice in group 3 (AOM + quercetin). As shown in Table

213 , the numbers of BCAC per $\mathrm{cm}^{2}$ in groups 2 (65\% inhibition, $\left.P<0.001\right)$, 3 (71\% 22 inhibition, $P<0.001)$, and 4 (64\% inhibition, $P<0.001)$ were significantly fewer than 23 that in group $1(12.5 \pm 9.7)$.

24 As summarized in Table 3, the mean PCNA-labeling indices of BCAC were greater 
Miyamoto 13

1 than those of ACF in groups 1 through 4. ACF indices in the mice that received dietary

2 flavonoids (28\% reduction by chrysin, $P<0.05$; 30\% reduction by quercetin, $P<0.001$;

3 and $20 \%$ reduction by nobiletin, $P<0.05$ ) were significantly smaller than that of mice

4 that received AOM alone (group 1, $39.1 \pm 5.2)$. Also, feeding with chrysin (26\%

5 reduction, $P<0.001$ ), quercetin (41\% reduction, $P<0.001$ ), and nobiletin (19\%

6 reduction, $P<0.001$ ) significantly lowered index for BCAC when compared with group

$7 \quad 1(48.8 \pm 6.0)$

8

9 Serum levels of leptin, adiponectin, IGF-1, insulin, triglyceride, cholesterol, and 10 glucose

11 Serum profile data are listed in Table 4. The serum concentration of leptin in group

121 was significantly greater $(67 \%$ increase) than that in group 8 (untreated, $P<0.05$ ),

13 while dietary administration of quercetin significantly decreased the serum leptin level

14 by $31 \%(P<0.05)$ when compared with group 1 . Chrysin feeding also decreased the

15 serum leptin level (11\% decrease), though it was not significant. Dietary nobiletin did

16 not have an effect on the level of leptin in serum. The serum level of adiponectin in

17 group 1 was significantly higher than that in group $8(P<0.05)$. However, dietary

18 administration with the flavonoids (groups 2 through 4) did not have any effects on

19 serum adiponectin levels. The serum level of IGF-1 in group 1 was comparable to that

20 in group 8. Dietary flavonoids (groups 2 through 4) decreased the level, though the

21 differences were not significant. Treatment with the different flavonoids did not have a

22 significant effect on the increase of insulin in serum caused by AOM administration.

23 There were no marked differences in regard to the levels of triglyceride, cholesterol, and 24 glucose among the groups. 
Miyamoto 14

1

2 Quercetin inhibition of leptin mRNA expression

The Akt/mTOR signaling pathway, including eIF4B, is considered to play a crucial

4 role as a regulator of adipogenesis [32] and leptin secretion [33]. Our previous study

5 indicated that nobiletin decreased the phosphorylation state of eIF4B partly through

6 inactivation of MEK/ERK [34]. Therefore, we investigated the effects of quercetin on

7 the mTOR signaling pathway, because it exhibited a profound suppressive effect on

8 leptin production in vivo. Unexpectedly, the phosphorylation state of Akt, ERK, eIF4B,

9 and S6 was increased in quercetin-treated cells, while nobiletin abolished the increase,

10 as previously reported [34] (Figure 2A). The differing effects obtained by treatments

11 with quercetin and nobiletin led us to examine whether quercetin has an effect on the expression of leptin mRNA. It is well known that CCAAT/enhancer binding protein

13 (C/EBP) $\alpha$ is an important transcription factor of leptin. Peroxisome proliferator-

14 activated receptor (PPAR) $\gamma$ plays an important role in adipocyte differentiation, though

15 several PPAR $\gamma$ agonists, including thiazolidinediones, were shown to repress leptin gene

16 expression in adipocytes [35]. In the present study, quercetin and troglitazone

17 significantly reduced leptin mRNA expression, while they did not reduce the level of

$18 \mathrm{C} / \mathrm{EBP} \alpha$ expression (Figure 2B). Of interest, inverse correlations for mRNA expression

19 between leptin and PPAR $\gamma$ were observed for quercetin and troglitazone (Figure 2B).

\section{Discussion}

Our results clearly indicate that dietary administration of the flavonoids chrysin, quercetin, and nobiletin leads to suppression of the development of precursor lesions 
1 (ACF and BCAC) induced by AOM in obese mice, in part by reducing the proliferation

2 activity of the lesions. The order of chemopreventive ability in the present findings was

3 quercetin $>$ chrysin $>$ nobiletin, which is consistent with our previous reports [16, 25].

4 Interestingly, the tested flavonoids, particularly quercetin, lowered the levels of growth

5 factors in serum, especially leptin.

6 The high susceptibility of $d b / d b$ mice to colon carcinogenesis might be related to

7 high proliferation activities of normal crypts and pre-neoplasms. Obesity itself along

8 with high levels of serum cholesterol, triglycerides, glucose, insulin, and leptin have

9 been suggested to explain that elevated susceptibility [25]. Recently, leptin was reported

10 to act as a mitogenic factor in cultured human colon cancer cells [36] and mouse colon

11 carcinogenesis [34]. Hyperinsulinemia has also been hypothesized to be an underlying

12 factor linking obesity, type 2 diabetes mellitus, and colon tumorigenesis [37]. As for the

13 mechanism of action, insulin resistance is associated with hyperinsulinemia and

14 increased levels of growth factors including IGF-1, which may promote colon

15 carcinogenesis through their effects on colonic cryptal cell kinetics [38]. In this context,

16 a recent report showing that leptin interacts with IGFs to promote the survival and

17 expansion of APC deficient colonic epithelial cells, but not of those expressing 18 wild-type $A P C$, is interesting [39].

19 In the present study, the tested dietary flavonoids did not have effects on body weight gain, epididymal fat pad weight, or food intake. However, quercetin markedly

21 lowered serum leptin and insulin concentrations, which were elevated by injection of

22 AOM. Importantly, treatment with each flavonoid alone (groups 5 through 7) did not

23 have an influence on the level of leptin as compared with the control group (Table 4).

24 However, feeding with the flavonoids decreased the serum levels of IGF-1. Although, it 
Miyamoto 16

1 is not clear how each of the flavonoids in this study reduces the serum concentrations of

2 these growth factors, such reduction may lead to suppression of proliferation activity in

3 preneoplastic lesions. Quercetin modulates several signal transduction pathways

4 involving MEK/ERK, which are associated with proliferation of several types of cancer

5 cells [40], while nobiletin inhibits the proliferation of a variety of human cancer cell

6 lines, partly due to induction of G1 cell cycle arrest [41]. In addition, chrysin induces

7 G2/M cell-cycle arrest in human colon carcinoma SW480 cells [42]. Together with our

8 findings, it is suggested that the reduction of proliferation in preneoplastic lesions (ACF

9 and BCAC) caused by each flavonoid is related to induction of cell-cycle arrest in 10 aberrant cells.

11 Leptin release is influenced by the amount of leptin mRNA expression in adipocytes.

12 That release is regulated by not only the mTOR signaling pathway, but also leptin

13 mRNA transcription, which is activated during adipocyte differentiation. C/EBP $\alpha$,

14 which belongs to the C/EBP family of transcription factors, plays a central role in the

15 control of energy homeostasis and is expressed during the terminal phase of

16 differentiation immediately prior to the expression of many adipose-specific genes [43].

17 The PPAR family of proteins also plays an important role in adipocyte differentiation

18 [44]. Taken together, logical candidate transactivators of the leptin promoter include

$19 \mathrm{C} / \mathrm{EBP} \alpha$ and PPAR $\gamma$. In fact, the proximal promoter of the leptin gene contains a

20 functional C/EBP-binding site, which mediates activation of the leptin promoter by

21 co-transfected $\mathrm{C} / \mathrm{EBP} \alpha$ in 3T3-L1 pre-adipocytes. However, it is surprising that PPAR $\gamma$

22 agonists, e.g., thiazolidinediones, were found to down-regulate leptin mRNA levels [35].

23 Furthermore, since the putative PPAR $\gamma$ response element in the leptin promoter is not 24 involved in negative regulation, it has been hypothesized that PPAR $\gamma$ functionally 
1 colonic malignancies.

antagonizes $\mathrm{C} / \mathrm{EBP} \alpha$ to decrease transcription in response to thiazolidinediones [45].

In the present study, quercetin significantly reduced the mRNA expression of leptin, but not that of $\mathrm{C} / \mathrm{EBP} \alpha$, while it up-regulated PPAR $\gamma$ mRNA expression, as did troglitazone (Figure 2B). Consistent with our findings, Fang et al. recently reported that quercetin inhibited insulin-stimulated glucose uptake in 3T3-L1 adipocytes by acting as a potential agonist of PPAR $\gamma$ [46]. Furthermore, their competitive ligand-binding assay confirmed that quercetin competes with rosiglitazone in the same binding pocket site as PPAR $\gamma$. Thus, it is likely that quercetin affects leptin secretion from white adipose tissue in $d b / d b$ mice by acting as a PPAR $\gamma$ agonist. We previously observed that nobiletin suppresses hyperleptinemia in ICR mice given AOM and dextran sulfate sodium [34]. However, no effects of nobiletin were found in the present $d b / d b$ mice that received AOM (Table 4). Since nobiletin suppresses leptin secretion partly by repression of the insulin signaling pathway in 3T3-L1 cells, the differences between the biochemical effects induced by quercetin and nobiletin may explain why the former and not the latter suppresses serum leptin levels in AOM-treated $d b / d b$ mice.

In summary, the present results provide additional evidence that certain daietary flavonoids are potent to inhibit the early phase of colon carcinogenesis in genetically altered obese mice, partly through reduction of proliferation. Those effects were also shown to be related to lowered serum levels of leptin, insulin, and IGF-1. This study investigated the effects of selected flavonoids on colonic pre-malignancy by focusing on lowered levels of serum growth factors, thus additional studies of the exact mechanisms are needed for development of prevention and treatment strategies for obesity-related 


\section{Acknowledgements}

2 This study was partly supported by Grants-in-Aid for Cancer Research from the

3 Ministry of Health, Labor and Welfare of Japan (to A. M. and T. T.) and for Japan

4 Society for the Promotion of Science (to A. M. and S. M.).

5

6 
Miyamoto 19

\section{References}

2 [1] S. Abu-Abid, A. Szold, J. Klausner, Obesity and cancer., J Med 33(1-4) (2002)

3 73-86.

4 [2] D. McMillan, N. Sattar, C. McArdle, ABC of obesity. Obesity and cancer., $5 \quad$ BMJ 333(7578) (2006) 1109-1111.

6 [3] S. Yakar, N. Nunez, P. Pennisi, P. Brodt, H. Sun, L. Fallavollita, H. Zhao, L. 7 Scavo, R. Novosyadlyy, N. Kurshan, B. Stannard, J. East-Palmer, N. Smith, S. Perkins,

8 R. Fuchs-Young, J. Barrett, S. Hursting, D. LeRoith, Increased tumor growth in mice 9 with diet-induced obesity: impact of ovarian hormones., Endocrinology 147(12) (2006) $10 \quad 5826-5834$.

11 [4] S. Hursting, J. Lavigne, D. Berrigan, S. Perkins, J. Barrett, Calorie restriction, 12 aging, and cancer prevention: mechanisms of action and applicability to humans., Annu 13 Rev Med 54 (2003) 131-152.

14 [5] Y. Zhang, R. Proenca, M. Maffei, M. Barone, L. Leopold, J. Friedman, 15 Positional cloning of the mouse obese gene and its human homologue., Nature $16 \quad 372(6505)(1994)$ 425-432.

17 [6] J. Kolaczynski, J. Ohannesian, R. Considine, C. Marco, J. Caro, Response of 18 leptin to short-term and prolonged overfeeding in humans., J Clin Endocrinol Metab 19 81(11) (1996) 4162-4165.

20 [7] M. Sinha, J. Ohannesian, M. Heiman, A. Kriauciunas, T. Stephens, S. Magosin, 21 C. Marco, J. Caro, Nocturnal rise of leptin in lean, obese, and non-insulin-dependent 22 diabetes mellitus subjects., J Clin Invest 97(5) (1996) 1344-1347.

23 [8] J. Potter, Colorectal cancer: molecules and populations., J Natl Cancer Inst 24 91(11) (1999) 916-932. 
3 the diabetes gene encodes the leptin receptor: identification of a mutation in the leptin

4 receptor gene in db/db mice., Cell 84(3) (1996) 491-495.

5 [10] P. Nishina, S. Lowe, J. Wang, B. Paigen, Characterization of plasma lipids in 6 genetically obese mice: the mutants obese, diabetes, fat, tubby, and lethal yellow., $7 \quad$ Metabolism 43(5) (1994) 549-553.

8 [11] C. Garofalo, E. Surmacz, Leptin and cancer., J Cell Physiol 207(1) (2006) $9 \quad 12-22$.

10 [12] J. Hardwick, G. Van Den Brink, G. Offerhaus, S. Van Deventer, M. 11 Peppelenbosch, Leptin is a growth factor for colonic epithelial cells., Gastroenterology 12 121(1) (2001) 79-90.

13 [13] Z. Liu, T. Uesaka, H. Watanabe, N. Kato, High fat diet enhances colonic cell 14 proliferation and carcinogenesis in rats by elevating serum leptin., Int J Oncol 19(5) 15 (2001) 1009-1014.

16 [14] B. Havsteen, Flavonoids, a class of natural products of high pharmacological 17 potency., Biochem Pharmacol 32(7) (1983) 1141-1148.

18 [15] A. Mora, M. Payá, J. Ríos, M. Alcaraz, Structure-activity relationships of 19 polymethoxyflavones and other flavonoids as inhibitors of non-enzymic lipid 20 peroxidation., Biochem Pharmacol 40(4) (1990) 793-797.

21 [16] S. Miyamoto, H. Kohno, R. Suzuki, S. Sugie, A. Murakami, H. Ohigashi, T. 22 Tanaka, Preventive effects of chrysin on the development of azoxymethane-induced 23 colonic aberrant crypt foci in rats., Oncol Rep 15(5) (2006) 1169-1173.

24 [17] T. Tanaka, K. Kawabata, S. Honjo, H. Kohno, M. Murakami, R. Shimada, K. 
1 Matsunaga, Y. Yamada, M. Shimizu, Inhibition of azoxymethane-induced aberrant crypt

2 foci in rats by natural compounds, caffeine, quercetin and morin., Oncol Rep 6(6)

3 (1999) 1333-1340.

4 [18] R. Suzuki, H. Kohno, A. Murakami, K. Koshimizu, H. Ohigashi, M. Yano, H.

5 Tokuda, H. Nishino, T. Tanaka, Citrus nobiletin inhibits azoxymethane-induced large

6 bowel carcinogenesis in rats., Biofactors 22(1-4) (2004) 111-114.

7 [19] N. Hasegawa, N. Yamda, M. Mori, Powdered green tea has antilipogenic effect

8 on Zucker rats fed a high-fat diet., Phytother Res 17(5) (2003) 477-480.

9 [20] Y. Ito, T. Ichikawa, Y. Morohoshi, T. Nakamura, Y. Saegusa, K. Ishihara, Effect 10 of tea catechins on body fat accumulation in rats fed a normal diet., Biomed Res 29(1) 11 (2008) 27-32.

12 [21] C. Hsu, G. Yen, Induction of cell apoptosis in 3T3-L1 pre-adipocytes by

13 flavonoids is associated with their antioxidant activity., Mol Nutr Food Res 50(11) 14 (2006) 1072-1079.

15 [22] R. Bird, C. Good, The significance of aberrant crypt foci in understanding the 16 pathogenesis of colon cancer., Toxicol Lett 112-113 (2000) 395-402.

17 [23] Y. Yamada, H. Mori, Pre-cancerous lesions for colorectal cancers in rodents: a 18 new concept., Carcinogenesis 24(6) (2003) 1015-1019.

19 [24] N. Niho, M. Takahashi, T. Kitamura, Y. Shoji, M. Itoh, T. Noda, T. Sugimura, K.

20 Wakabayashi, Concomitant suppression of hyperlipidemia and intestinal polyp 21 formation in Apc-deficient mice by peroxisome proliferator-activated receptor ligands., 22 Cancer Res 63(18) (2003) 6090-6095.

23 [25] K. Hayashi, R. Suzuki, S. Miyamoto, Y. Shin-Ichiroh, H. Kohno, S. Sugie, S. 24 Takashima, T. Tanaka, Citrus auraptene suppresses azoxymethane-induced colonic 
1 preneoplastic lesions in C57BL/KsJ-db/db mice., Nutr Cancer 58(1) (2007) 75-84.

2 [26] H. Maeda, M. Hosokawa, T. Sashima, N. Takahashi, T. Kawada, K. Miyashita,

3 Fucoxanthin and its metabolite, fucoxanthinol, suppress adipocyte differentiation in

4 3T3-L1 cells., Int J Mol Med 18(1) (2006) 147-152.

5 [27] T. Tanaka, K. Kawabata, M. Kakumoto, H. Makita, A. Hara, H. Mori, K. Satoh,

6 A. Murakami, W. Kuki, Y. Takahashi, H. Yonei, K. Koshimizu, H. Ohigashi, Citrus

7 auraptene inhibits chemically induced colonic aberrant crypt foci in male F344 rats.,

8 Carcinogenesis 18(11) (1997) 2155-2161.

9 [28] Y. Hirose, T. Kuno, Y. Yamada, K. Sakata, M. Katayama, K. Yoshida, Z. Qiao,

10 K. Hata, N. Yoshimi, H. Mori, Azoxymethane-induced beta-catenin-accumulated crypts

11 in colonic mucosa of rodents as an intermediate biomarker for colon carcinogenesis.,

12 Carcinogenesis 24(1) (2003) 107-111.

13 [29] E. McLellan, A. Medline, R. Bird, Sequential analyses of the growth and 14 morphological characteristics of aberrant crypt foci: putative preneoplastic lesions., 15 Cancer Res 51(19) (1991) 5270-5274.

16 [30] T. Pretlow, M. O'Riordan, G. Somich, S. Amini, T. Pretlow, Aberrant crypts 17 correlate with tumor incidence in F344 rats treated with azoxymethane and phytate., 18 Carcinogenesis 13(9) (1992) 1509-1512.

19 [31] R. Bird, Role of aberrant crypt foci in understanding the pathogenesis of colon 20 cancer., Cancer Lett 93(1) (1995) 55-71.

21 [32] J. Kim, J. Chen, regulation of peroxisome proliferator-activated 22 receptor-gamma activity by mammalian target of rapamycin and amino acids in 23 adipogenesis., Diabetes 53(11) (2004) 2748-2756.

24 [33] T. Szkudelski, Intracellular mediators in regulation of leptin secretion from 
Miyamoto 23

1 adipocytes., Physiol Res (2006).

2 [34] S. Miyamoto, Y. Yasui, T. Tanaka, H. Ohigashi, A. Murakami, Suppressive

3 effects of nobiletin on hyperleptinemia and colitis-related colon carcinogenesis in male

4 ICR mice., Carcinogenesis 29(5) (2008) 1057-1063.

5 [35] B. Zhang, M. Graziano, T. Doebber, M. Leibowitz, S. White-Carrington, D.

6 Szalkowski, P. Hey, M. Wu, C. Cullinan, P. Bailey, B. Lollmann, R. Frederich, J. Flier,

7 C. Strader, R. Smith, Down-regulation of the expression of the obese gene by an

8 antidiabetic thiazolidinedione in Zucker diabetic fatty rats and $\mathrm{db} / \mathrm{db}$ mice., J Biol Chem

$9 \quad$ 271(16) (1996) 9455-9459.

10 [36] O. Ogunwobi, I. Beales, The anti-apoptotic and growth stimulatory actions of

11 leptin in human colon cancer cells involves activation of JNK mitogen activated protein

12 kinase, JAK2 and PI3 kinase/Akt., Int J Colorectal Dis 22(4) (2007) 401-409.

13 [37] R. Kaaks, A. Lukanova, Energy balance and cancer: the role of insulin and

14 insulin-like growth factor-I., Proc Nutr Soc 60(1) (2001) 91-106.

15 [38] M. Moore, T. Sobue, K. Kuriki, K. Tajima, S. Tokudome, S. Kono, Comparison 16 of Japanese, American-Whites and African-Americans--pointers to risk factors to 17 underlying distribution of tumours in the colorectum., Asian Pac J Cancer Prev 6(3) 18 (2005) 412-419.

19 [39] J. Fenton, N. Hord, J. Lavigne, S. Perkins, S. Hursting, Leptin, insulin-like 20 growth factor-1, and insulin-like growth factor-2 are mitogens in ApcMin/+ but not $21 \mathrm{Apc}+/+$ colonic epithelial cell lines., Cancer Epidemiol Biomarkers Prev 14(7) (2005) 22 1646-1652.

23 [40] A. Murakami, H. Ashida, J. Terao, Multitargeted cancer prevention by 24 quercetin., Cancer Lett 269(2) (2008) 315-325. 
Miyamoto 24

1 [41] K. Morley, P. Ferguson, J. Koropatnick, Tangeretin and nobiletin induce G1

2 cell cycle arrest but not apoptosis in human breast and colon cancer cells., Cancer Lett $3 \quad$ 251(1) (2007) 168-178.

4 [42] W. Wang, P. VanAlstyne, K. Irons, S. Chen, J. Stewart, D. Birt, Individual and

5 interactive effects of apigenin analogs on G2/M cell-cycle arrest in human colon

6 carcinoma cell lines., Nutr Cancer 48(1) (2004) 106-114.

7 [43] M. Lane, Q. Tang, M. Jiang, Role of the CCAAT enhancer binding proteins

8 (C/EBPs) in adipocyte differentiation., Biochem Biophys Res Commun 266(3) (1999)

$9 \quad 677-683$.

10 [44] A. Chawla, E. Schwarz, D. Dimaculangan, M. Lazar, Peroxisome

11 proliferator-activated receptor (PPAR) gamma: adipose-predominant expression and 12 induction early in adipocyte differentiation., Endocrinology 135(2) (1994) 798-800.

13 [45] A. Hollenberg, V. Susulic, J. Madura, B. Zhang, D. Moller, P. Tontonoz, P.

14 Sarraf, B. Spiegelman, B. Lowell, Functional antagonism between CCAAT/Enhancer

15 binding protein-alpha and peroxisome proliferator-activated receptor-gamma on the 16 leptin promoter., J Biol Chem 272(8) (1997) 5283-5290.

17 [46] X. Fang, J. Gao, D. Zhu, Kaempferol and quercetin isolated from Euonymus 18 alatus improve glucose uptake of 3T3-L1 cells without adipogenesis activity., Life Sci 19 82(11-12) (2008) 615-622. 
Miyamoto 25

\section{Figure legends}

2

3 Fig. 1. (A) Chemical structures of the studied flavonoids. (B) Modulatory effects of the flavonoids on leptin secretion from 3T3-L1 cells. 3T3-L1 mouse pre-adipocytes were induced to adipocyte differentiation with a mixture of methylisobutylxanthine $(0.5 \mathrm{mM})$, dexamethasone $(1 \mu \mathrm{M})$, and insulin (10 $\mu \mathrm{g} / \mathrm{ml}$ ) in DMEM containing 10\% FBS for 48 hours. Differentiated 3T3-L1 cells were treated with DMSO alone or various concentrations of nobiletin for 12 days, then the supernatants were removed for measurements of leptin. The cells were washed twice with PBS and stained with Oil Red-O. Stained cells were viewed under an inverted microscope (Leica Microsystems, Tokyo, Japan) (original magnification 1: 200). Leptin secretion was quantified by ELISA. Values are shown as the mean \pm SD. Statistical analysis was performed using Student's $t$-test: $P<0.05$.

Fig. 2. (A) Modulatory effects of quercetin, nobiletin, and rapamycin on the Akt/mTOR signaling pathway in differentiated 3T3-L1 cells. (B) Modulatory effects of quercetin and troglitazone on the expression of transcription factors in differentiated 3T3-L1 cells. 3T3-L1 mouse pre-adipocytes $\left(1 \times 10^{5}\right.$ cells in 35 $\mathrm{mm}$ dish) were induced to adipocyte differentiation with a mixture of methylisobutylxanthine $(0.5 \mathrm{mM})$, dexamethasone $(1 \mu \mathrm{M})$, and insulin (10 $\mu \mathrm{g} / \mathrm{ml}$ ) in DMEM containing 10\% FBS for 48 hours. Differentiated 3T3-L1 cells were treated with DMSO alone, quercetin, nobiletin, or rapamycin for 12 days. The cells were washed twice with PBS and analyzed using western blotting and 
RT-PCR methods. Rap, rapamycin.

Miyamoto 26 
Table 1. List of primer sequences for RT-PCR

\begin{tabular}{|c|c|c|c|c|c|}
\hline Gene & Primer & Sequence (5'-3’) & Product size (bp) & Cycles & $\begin{array}{l}\text { Denaturation } \\
\text { Annealing } \quad\left({ }^{\circ} \mathrm{C}, \mathrm{sec}\right) \\
\text { Extention }\end{array}$ \\
\hline Leptin & $\begin{array}{l}\text { Forward } \\
\text { Reverse }\end{array}$ & $\begin{array}{l}\text { CCA AAA CCC TCA TCA AGA CC } \\
\text { GTC CAA CTG TTG AAG AAT GTC CC }\end{array}$ & 395 & 37 & $\begin{array}{l}95,45 \\
57,45 \\
72,45\end{array}$ \\
\hline$C / E B P \alpha$ & $\begin{array}{l}\text { Forward } \\
\text { Reverse }\end{array}$ & $\begin{array}{l}\text { AGG TGC TGG AGT TGA CCA GT } \\
\text { CAG CCT AGA GAT CCA GCG AC }\end{array}$ & 238 & 25 & $\begin{array}{l}94,60 \\
54,60 \\
72,30\end{array}$ \\
\hline PPAR $\gamma$ & $\begin{array}{l}\text { Forward } \\
\text { Reverse }\end{array}$ & $\begin{array}{l}\text { GGT GAA ACT CTG GGA GAT TC } \\
\text { CAA CCA TTG GGT CAG CTC TT }\end{array}$ & 268 & 30 & $\begin{array}{l}94,40 \\
58,40 \\
72,50\end{array}$ \\
\hline Cyclophilin & $\begin{array}{c}\text { Forward } \\
\text { Reverse }\end{array}$ & $\begin{array}{l}\text { TTG GGT CGC GTC TCG TTC GA } \\
\text { GCC AGG ACC TGT ATG CTT CA }\end{array}$ & 240 & 20 & $\begin{array}{l}95,30 \\
50,30 \\
72,60\end{array}$ \\
\hline
\end{tabular}


Table 2. General observations in male $d b / d b$ mice

\begin{tabular}{|c|c|c|c|c|c|c|}
\hline $\begin{array}{c}\text { Group } \\
\text { No. }\end{array}$ & Treatment & $\begin{array}{c}\text { Body weight } \\
\text { (g) }\end{array}$ & $\begin{array}{c}\text { Epididymal fat } \\
\text { weight (g) }\end{array}$ & $\begin{array}{l}\text { Pancreatic weights } \\
\text { (g/100g body weight) }\end{array}$ & $\begin{array}{l}\text { Length of large bowel } \\
\text { (cm) }\end{array}$ & $\begin{array}{c}\text { Food intake } \\
\text { (g/day) }\end{array}$ \\
\hline 1 & AOM & $48.6 \pm 3.3$ & $2.42 \pm 0.22$ & $0.530 \pm 0.078$ & $11.8 \pm 0.4$ & $6.30 \pm 1.66$ \\
\hline 2 & $\begin{array}{c}\text { AOM+ } \\
100 \text { ppm CHR }\end{array}$ & $47.7 \pm 5.3$ & $2.31 \pm 0.28$ & $0.661 \pm 0.127$ & $11.9 \pm 0.4$ & $5.70 \pm 1.88$ \\
\hline 3 & $\begin{array}{c}\text { AOM+ } \\
100 \text { ppm QER }\end{array}$ & $48.8 \pm 2.1$ & $2.45 \pm 0.31$ & $0.666 \pm 0.083^{a}$ & $12.1 \pm 0.3$ & $6.26 \pm 1.77$ \\
\hline 4 & $\begin{array}{c}\text { AOM+ } \\
100 \text { ppm NOB }\end{array}$ & $53.3 \pm 3.3$ & $2.47 \pm 0.40$ & $0.555 \pm 0.013$ & $12.1 \pm 0.4$ & $5.83 \pm 1.92$ \\
\hline 5 & 100 ppm CHR & $43.3 \pm 9.2$ & $2.42 \pm 0.35$ & $0.802 \pm 0.205^{a}$ & $11.6 \pm 0.7$ & $6.86 \pm 2.03$ \\
\hline 6 & 100 ppm QER & $47.9 \pm 7.2$ & $2.63 \pm 0.35$ & $0.750 \pm 0.209$ & $11.6 \pm 0.4$ & $6.93 \pm 2.39$ \\
\hline 7 & 100 ppm NOB & $46.9 \pm 8.0$ & $2.38 \pm 0.36$ & $0.740 \pm 0.057^{\mathrm{a}}$ & $11.9 \pm 0.5$ & $6.59 \pm 1.94$ \\
\hline 8 & None & $48.7 \pm 9.5$ & $2.35 \pm 0.46$ & $0.686 \pm 0.162$ & $11.5 \pm 1.0$ & $6.48 \pm 2.07$ \\
\hline
\end{tabular}

Data are shown as the mean \pm SD.

${ }^{\text {a }}$ Significantly different in Student's $t$-test, $P<0.05$ vs group 1 . 
Table 3. Inhibitory effects of flavonoids on AOM-induced preneoplastic lesion formation and PCNA-index

\begin{tabular}{|c|c|c|c|c|c|c|}
\hline \multirow{2}{*}{$\begin{array}{l}\text { Group } \\
\text { No. }\end{array}$} & \multirow{2}{*}{ Treatment } & \multirow{2}{*}{ Total no. of ACF/colon } & \multirow{2}{*}{$\begin{array}{l}\text { Total no. of ACF containing } \\
4 \text { or more ACs/colon }\end{array}$} & \multirow{2}{*}{$\begin{array}{l}\text { Total no. of } \\
\text { BCAC } / \mathbf{c m}^{2}\end{array}$} & \multicolumn{2}{|c|}{ PCNA-labeling index (\%) } \\
\hline & & & & & $\overline{A C F}$ & BCAC \\
\hline 1 & AOM & $25.6 \pm 8.9$ & $4.6 \pm 2.4$ & $12.5 \pm 9.7$ & $39.1 \pm 5.2$ & $48.8 \pm 6.0$ \\
\hline 2 & $\begin{array}{c}\text { AOM+ } \\
100 \text { ppm CHR }\end{array}$ & $2.3 \pm 2.2^{\mathrm{a}}$ & $0.1 \pm 0.3^{\mathrm{a}}$ & $4.4 \pm 3.1^{\mathrm{b}}$ & $30.5 \pm 6.2^{b}$ & $35.9 \pm 6.3^{\prime}$ \\
\hline 3 & $\begin{array}{c}\text { AOM+ } \\
100 \text { ppm QER }\end{array}$ & $2.8 \pm 2.0^{\mathrm{a}}$ & $\mathbf{0}$ & $3.6 \pm 2.6^{c}$ & $27.5 \pm 6.3^{\mathrm{a}}$ & $28.7 \pm 9.2^{2}$ \\
\hline 4 & $\begin{array}{c}\text { AOM+ } \\
100 \text { ppm NOB }\end{array}$ & $8.3 \pm 4.9^{\mathrm{a}}$ & $0.7 \pm 1.3^{\mathrm{a}}$ & $4.5 \pm 3.2^{b}$ & $31.4 \pm 6.2^{\mathrm{b}}$ & $39.5 \pm 6.9$ \\
\hline 5 & 100 ppm CHR & $\mathbf{0}$ & $\mathbf{0}$ & $\mathbf{0}$ & $\mathbf{0}$ & $\mathbf{0}$ \\
\hline 6 & 100 ppm QER & $\mathbf{0}$ & $\mathbf{0}$ & $\mathbf{0}$ & $\mathbf{0}$ & $\mathbf{0}$ \\
\hline 7 & 100 ppm NOB & $\mathbf{0}$ & $\mathbf{0}$ & $\mathbf{0}$ & $\mathbf{0}$ & $\mathbf{0}$ \\
\hline 8 & None & $\mathbf{0}$ & $\mathbf{0}$ & $\mathbf{0}$ & $\mathbf{0}$ & $\mathbf{0}$ \\
\hline
\end{tabular}

Data are shown as the mean \pm SD.

${ }^{\text {a }}$ Significantly different in one-way ANOVA with Bonferroni correction test, $P<0.001$ vs group 1 .

${ }^{\mathrm{b}}$ Significantly different in one-way ANOVA with Bonferroni correction test, $P<0.05$ vs group 1 .

${ }^{\mathrm{c}}$ Significantly different in one-way ANOVA with Bonferroni correction test, $P<0.01$ vs group 1. 
Table 4. Serum profiles in each groups of male $d b / d b$ mice

\begin{tabular}{|c|c|c|c|c|c|c|c|c|}
\hline $\begin{array}{c}\text { Group } \\
\text { No. }\end{array}$ & Treatment & $\begin{array}{l}\text { Leptin } \\
\text { (ng/ml) }\end{array}$ & $\begin{array}{c}\text { Adiponectin } \\
(\mu \mathrm{g} / \mathrm{ml})\end{array}$ & $\begin{array}{l}\text { IGF-1 } \\
(\mathrm{ng} / \mathrm{ml})\end{array}$ & $\begin{array}{l}\text { Insulin } \\
\text { (ng/ml) }\end{array}$ & $\begin{array}{c}\text { Triglyceride } \\
\text { (mg/dl) }\end{array}$ & $\begin{array}{c}\text { Cholesterol } \\
\text { (mg/dl) }\end{array}$ & $\begin{array}{l}\text { Glucose } \\
\text { (mg/dl) }\end{array}$ \\
\hline 1 & AOM & $181.4 \pm 15.6^{\mathrm{a}}$ & $8.0 \pm 0.3^{a}$ & $467.5 \pm 93.3$ & $4.2 \pm 2.6$ & $204.0 \pm 27.9$ & $176.4 \pm 13.0$ & $791.6 \pm 101.4$ \\
\hline 2 & $\begin{array}{c}\text { AOM+ } \\
100 \text { ppm CHR }\end{array}$ & $160.9 \pm 39.5$ & $8.1 \pm 0.2$ & $397.3 \pm 61.8$ & $4.6 \pm 1.9$ & $183.1 \pm 37.2$ & $169.5 \pm 13.8$ & $843.9 \pm 78.4$ \\
\hline 3 & $\begin{array}{c}\text { AOM+ } \\
100 \text { ppm QER }\end{array}$ & $125.4 \pm 19.3^{b}$ & $7.8 \pm 0.7$ & $434.2 \pm 53.2$ & $2.8 \pm 0.8$ & $227.4 \pm 44.2$ & $175.8 \pm 21.2$ & $882.0 \pm 20.6$ \\
\hline 4 & $\begin{array}{c}\text { AOM+ } \\
100 \text { ppm NOB }\end{array}$ & $179.2 \pm 44.3$ & $8.5 \pm 0.8$ & $412.2 \pm 49.8$ & $5.4 \pm 2.2$ & $248.8 \pm 66.7$ & $187.0 \pm 21.0$ & $817.4 \pm 59.4$ \\
\hline 5 & 100 ppm CHR & $102.3 \pm 51.0$ & $7.0 \pm 0.8$ & $538.2 \pm 175.8$ & $1.5 \pm 1.0$ & $277.3 \pm 94.7$ & $151.9 \pm 36.2$ & $1013.4 \pm 79.0$ \\
\hline 6 & 100 ppm QER & $100.8 \pm 44.9$ & $6.5 \pm 0.3$ & $495.8 \pm 95.4$ & $2.0 \pm 1.3$ & $250.4 \pm 61.8$ & $171.5 \pm 28.3$ & $966.8 \pm 94.0$ \\
\hline 7 & 100 ppm NOB & $102.6 \pm 35.9$ & $6.9 \pm 0.7$ & $528.1 \pm 114.0$ & $2.7 \pm 2.9$ & $243.7 \pm 17.5$ & $168.0 \pm 28.8$ & $886.7 \pm 102.5$ \\
\hline 8 & None & $108.8 \pm 36.8$ & $6.4 \pm 0.3$ & $473.0 \pm 35.7$ & $2.8 \pm 1.7$ & $275.0 \pm 15.9$ & $179.0 \pm 24.8$ & $1068.2 \pm 27.2$ \\
\hline
\end{tabular}

Data are shown as the mean \pm SD.

${ }^{a}$ Significantly different in Student's $t$-test, $P<0.05$ vs group 8 .

${ }^{\mathrm{b}}$ Significantly different in Student's $t$-test, $P<0.05$ vs group 1 . 
A

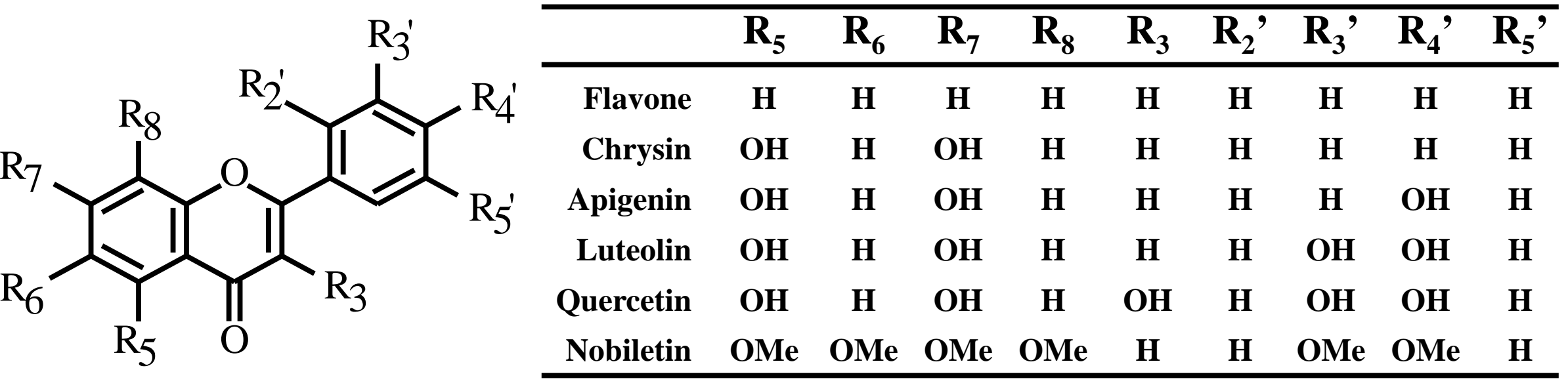

B
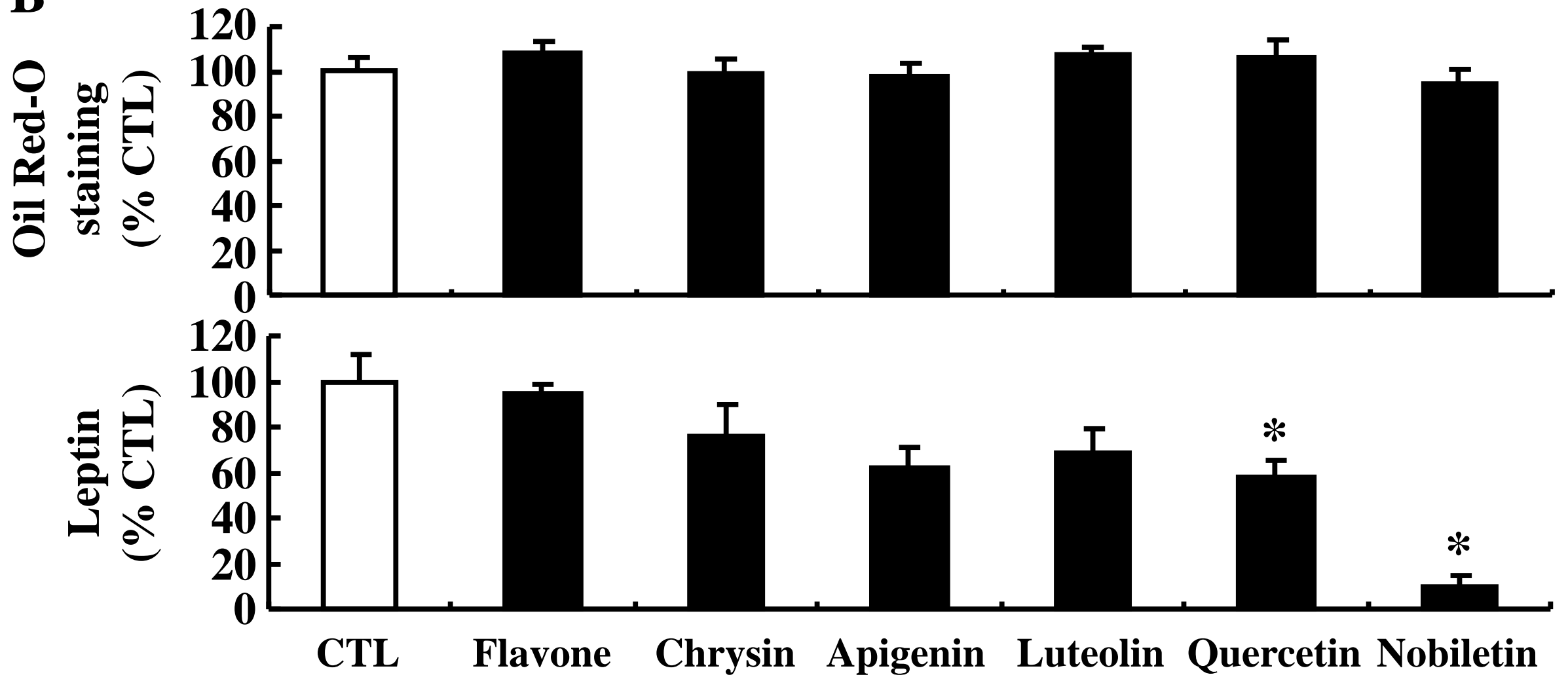
A

kDa

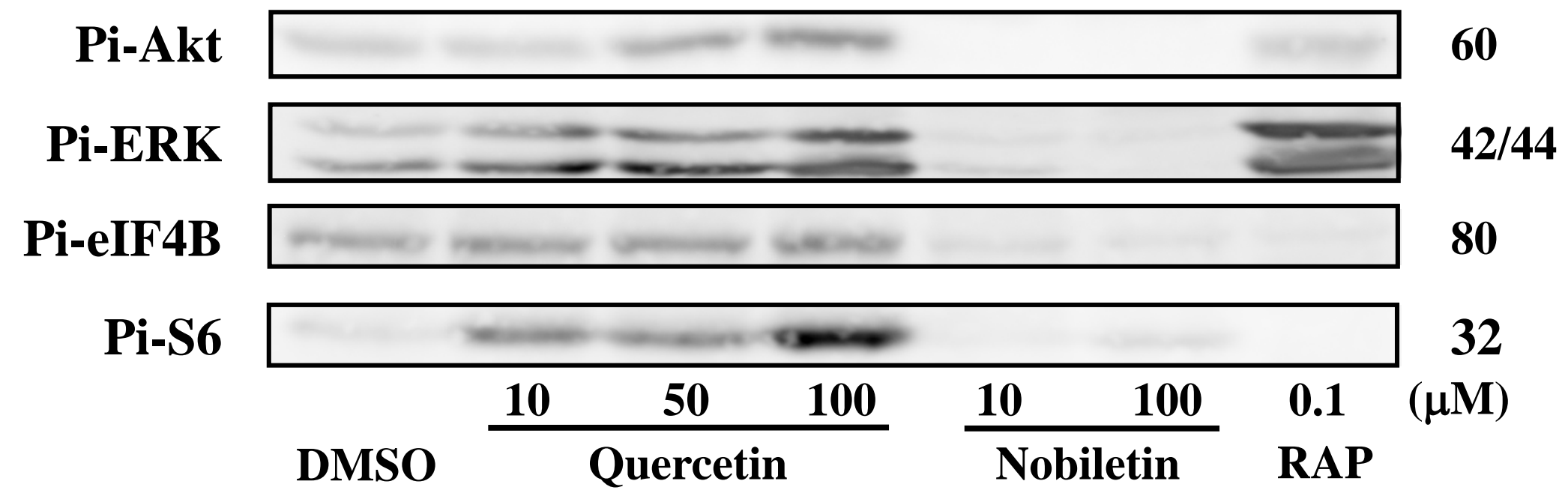

B

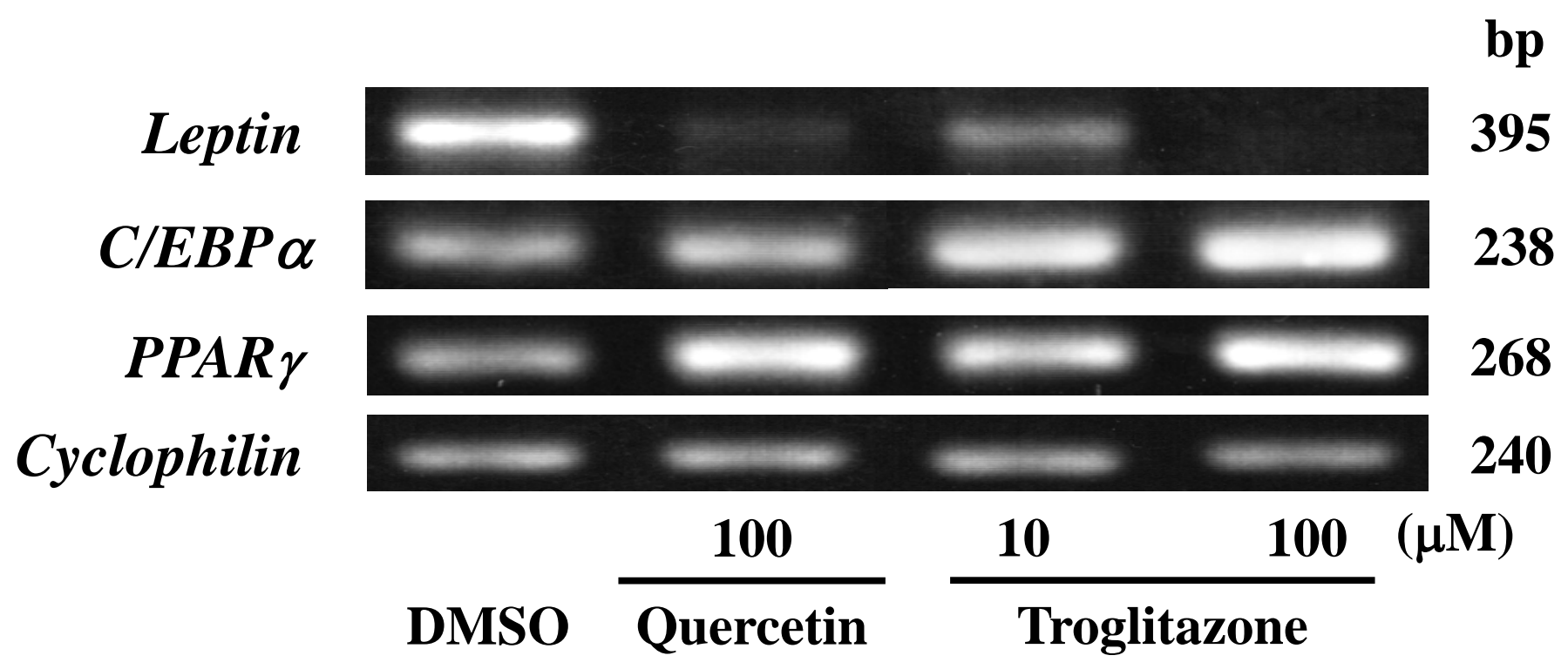

